\title{
Outcome of immediate postpartum intrauterine contraceptive device in caesarean versus vaginal insertion: a comparative study
}

\section{Aswathy Shanavas, Sujamol Jacob*, Nirmala Chellamma}

\author{
Department of Obstetrics and Gynecology, Sree Avittom Thirunal Hospital, Government Medical College, \\ Trivandrum, Kerala, India
}

Received: 27 November 2016

Accepted: 20 December 2016

\author{
*Correspondence: \\ Dr. Sujamol Jacob, \\ E-mail: minujohn63@gmail.com
}

Copyright: () the author(s), publisher and licensee Medip Academy. This is an open-access article distributed under the terms of the Creative Commons Attribution Non-Commercial License, which permits unrestricted non-commercial use, distribution, and reproduction in any medium, provided the original work is properly cited.

\begin{abstract}
Background: Immediate Postpartum Intrauterine Contraceptive device is a novel approach to contraception which integrates Maternal - Child health and family planning services. It is a postpartum method which provides long term reversible contraception to women before discharge from the delivery setting. More research is needed in the field of PPIUCD to enhance awareness and acceptance in the community. This study is designed to compare the safety and efficacy of PPIUCD inserted at cesarean versus vaginal delivery.

Methods: This is a prospective study conducted at Sree Avittom Thirunal Hospital, Govt. Medical College, and Kerala - A tertiary care teaching institution. A total of 126 patients with cesarean or vaginal deliveries had PPIUCD insertions and they were followed up for a period of one year. The outcome measures analyzed were safety measures - menstrual irregularities, vaginal discharge, pelvic infection and perforation and efficacy measures - failure, expulsion and removal. Data are expressed in frequency and percentage. Chi square test was used for comparison and $P$ value $<0.05$ was considered significant.

Results: The study shows that PPIUCD is an effective intervention in both cesarean and vaginal delivery with no significant differences in safety and efficacy depending on the route of insertion. There was no case of perforation or failure and no significant risk of infection in either group. Spontaneous expulsion occurred in two cases inserted by vaginal route. Missing string incidence is high in the cesarean group compared to vaginal insertion.

Conclusions: PPIUCD is a safe effective and convenient method of contraception and should be encouraged in both vaginal and cesarean deliveries.
\end{abstract}

Keywords: Intra uterine contraceptive device, Intra cesarean, Post placental, Postpartum contraception

\section{INTRODUCTION}

Optimal birth spacing and birth control are issues that caught the attention of global reproductive health services. Multiple studies show that adverse maternal and perinatal outcome is related to closely spaced pregnancies. Approximately $27 \%$ births in India occur $<24$ months after a previous birth and another 34\% between $24-35$ months. ${ }^{1} 61 \%$ of births in India occur at intervals shorter than the recommended birth-to- birth interval of 36 months. The study shows that $65 \%$ of women in the first year postpartum have an unmet need for family planning. Postpartum period is a highly vulnerable period for unintended pregnancy as there are limited contraceptive options for breastfeeding mothers. Moreover return of ovulation is highly unpredictable in those not on exclusive breastfeeding. So immediate postpartum is the ideal time to begin contraception as women is strongly motivated at this time.

Government of India has launched several programs which emphasizes on promotion of adequate birth spacing. In India where government is promoting institutional deliveries, also creates opportunities for 
providing quality postpartum family planning services. Intra uterine contraceptive devices have been used by women in India for decades. It is an ideal method for spacing births. Returning to postpartum services after delivery can present multiple challenges to mother who have competing demands. Taking advantage of immediate postpartum period for family planning acceptance overcomes multiple barriers of service provision. Postpartum IUCD is a method for obtaining long term reversible contraception before returning home.

The concept of immediate postpartum insertion of IUCD was revisited by the Ministry of Health and Family Welfare in collaboration with Jhpiego an international nonprofit health organization. The IUCD used is Copper T $380 \mathrm{~A}$, same as that for interval insertion. The advantage of its use in the immediate postpartum period are convenience and integration of services, certain that she is not pregnant at the time of insertion, highly motivated for a reliable spacing method, negligible risk of uterine perforation because of thick uterine wall and reduced perception of initial side effects like bleeding and cramping as she enters into lactational amenorrhea.

The main limitation in the early years of its introduction was the increased risk of spontaneous expulsion. The rates varied widely from 10 to $14 \%$. Meticulous attention to the correct insertion technique has significantly lowered the rate of expulsion in later years.

More studies are needed to address the misconceptions and negative attitudes which are still an issue at the community level. This study is conducted to examine the factors associated with acceptability according to their sociodemographic and obstetric characteristics and to analyze the safety and efficacy of PPIUCD inserted at cesarean and vaginal delivery and thereby improve the client satisfaction and continuation rates.

\section{METHODS}

After antenatal counselling, 126 patients who were willing to participate in the study were enrolled. Written informed consent was taken at the onset of labor. Vaginal or caesarean insertion of PPIUCD was done depending on their mode of delivery. Outcome measures were analyzed at follow up visits scheduled at 6 weeks 6 months and 1 year after insertion

The WHO medical eligibility criteria was the scientific foundation for client assessment and selection. ${ }^{2}$

Category 1: Immediate post placental - within $10 \mathrm{mts}$ of placental delivery.

Immediate postpartum <48 hours after delivery

During caesarean section

Category 2: No conditions
Category 3: Between $48 \mathrm{hrs}$ and 6 weeks postpartum

Chorioamnionitis

Prolonged rupture of membranes $>18$ hours

Category 4: Puerperal sepsis

Unresolved PPH

\section{Inclusion criteria}

Women delivering vaginally or by cesarean section having received counseling for PPIUCD contraception and given written informed consent.

Patients admitted directly to labour room in early labour were also counseled and included in the study.

\section{Exclusion criteria}

Patients belonging to MEC category 3 and 4 .

IUCD used was Copper T 380 A. Only doctors trained for insertion according to the national training programme were involved in the study. The correct fundal placement with long curved Kelly's placental forceps was highly emphasized. AMTSL was performed as routine. Post insertion counselling was given before discharge. This included IUCD client card showing type of IUCD, date of insertion and date of review, advice regarding side effects like irregular vaginal bleeding, foul smelling vaginal discharge, uterine cramping, fever and spontaneous expulsion. She was advised follow up at six weeks, six months and one year after insertion.

At follow up, outcome measures were studied in terms of safety, efficacy and missing strings. These outcomes were compared for vaginal and caesarean insertions.

\section{RESULTS}

A total of 126 women were enrolled in the study for PPIUCD, out of which 10 were excluded belonging to MEC category 3 and 4. PPIUCD was inserted in 116 participants. Out of which 58 were intra cesarean insertions and a comparable group of another 58 for vaginal insertions. 6 patients $(5.17 \%)$ were lost to follow up.

Majority of participants belonged to 20-25 years of age $(50.3 \%)$ and were from rural areas $(80.3 \%)$. Middle socio economic group $(70.7 \%)$ constituted the majority and $85.4 \%$ were primary or secondary school educated. Higher education group and professionals constituted only $14.6 \%$ showing the need for increased public awareness in order to convince the higher social strata. Evaluation of their clinical profile revealed that multi paras constituted the majority $(73.3 \%)$, while primi paras were very reluctant for PPIUCD (26.7\%). Among the 
primis, those undergoing caesarean had a higher percentage of acceptance $80.6 \%$, probably because of better spacing advantage after a caesarean section. Acceptance was better when counselled in early labour (56\%) compared to antenatal counselling (44\%).

Table 1: Socio demographic profile of acceptors.

\begin{tabular}{|lll|}
\hline & Frequency & $\begin{array}{l}\text { Percentage } \\
\text { N=116 }\end{array}$ \\
\hline Age (Years) & & \\
$<19$ & 4 & 3.4 \\
$20-25$ & 58 & 50 \\
$26-30$ & 37 & 31.8 \\
$31-35$ & 13 & 11.2 \\
$>35$ & 4 & 3.4 \\
\hline Educational status & & \\
No formal education & 0 & 0 \\
Primary & 27 & 23.3 \\
Secondary & 72 & 62.1 \\
Higher education & 17 & 14.6 \\
\hline Socio economic & & \\
status & 25 & 21.5 \\
Lower & 82 & 70.7 \\
Middle & 9 & 7.8 \\
High & & \\
\hline Residence & & 80.2 \\
Rural & 93 & 19.8 \\
Urban & 23 & 76.7 \\
\hline Religion & & 10.3 \\
Hindu & 89 & 12.9 \\
Christian & 12 & \\
Muslim & 15 & \\
\hline & & \\
\hline
\end{tabular}

Table 2: Obstetric profile of acceptors.

\begin{tabular}{|c|c|c|}
\hline & $\begin{array}{l}\text { Frequency } \\
\mathrm{N}=116\end{array}$ & $\begin{array}{l}\text { Percentage } \\
\%\end{array}$ \\
\hline \multicolumn{3}{|l|}{ Parity } \\
\hline Primi para & 31 & 26.7 \\
\hline Multi Para & 85 & 73.3 \\
\hline \multicolumn{3}{|l|}{ Gestational age } \\
\hline Term & 87 & 75 \\
\hline Preterm & 29 & 25 \\
\hline \multicolumn{3}{|l|}{ Time of counselling } \\
\hline Antenatal & 51 & 44 \\
\hline Early labour & 65 & 56 \\
\hline Postnatal' & 0 & 0 \\
\hline \multicolumn{3}{|l|}{ Route of insertion } \\
\hline Post placental (in 10mts) & 58 & 50 \\
\hline Postpartum (in 48 hrs) & 0 & 0 \\
\hline Intra caesarean & 58 & 50 \\
\hline
\end{tabular}

Follow up clinic attendance of PPIUCD were 110 (94.83\%). 16 patients (14.7\%) had menstrual problems in the form of irregular spotting and dysmenorrhoea, but only 5 patients $(4.3 \%)$ had persistent menorrhagia at the end of one year. 3 patients $(2.7 \%)$ had fever at 6 weeks follow up which was attributed to UTI, mastitis and
LRTI. No further episodes of fever at subsequent reviews. There was no case of puerperal sepsis or pelvic inflammatory disease. Vaginal discharge noticed by 2 patients was diagnosed as normal leucorrhoea and candidiasis which responded to reassurance and antifungal treatment respectively. There was no case of uterine perforation or IUCD failure in our study. 2 cases of expulsion occurred in the vaginal delivery group prior to six weeks follow up - could be due to improper fundal placement or string entangled in the Kellys forceps causing downward displacement. Beyond 6 weeks there was no spontaneous expulsion. Two patients insisted on removal at one year follow up due to persistent menorrhagia not relieved by tranexamic acid and husband's pressure for IUCD removal.

Table 3: Comparison of parity and route of insertion.

\begin{tabular}{|lllll|ll|}
\hline Parity & CS & $\%$ & Vaginal & $\%$ & $\begin{array}{l}\text { Total } \\
\text { no. }\end{array}$ & $\%$ \\
\hline Primi & 25 & 43.1 & 6 & 10.3 & 31 & 26.7 \\
\hline Multi & 33 & 56.9 & 52 & 89.7 & 85 & 73.3 \\
\hline Total & $\mathbf{5 8}$ & $\mathbf{1 0 0 . 0}$ & $\mathbf{5 8}$ & $\mathbf{1 0 0 . 0}$ & $\mathbf{1 1 6}$ & $\mathbf{1 0 0 . 0}$ \\
\hline
\end{tabular}

$\chi^{2}=15.892 ; \mathrm{df}=1 \mathrm{P}$ value $=<0.001$

Missing strings at follow up was a matter of concern for the patients. This was high in the caesarean group (48.5\%) compared to vaginal delivery group (25\%). This difference was statistically significant ( $\mathrm{p}$ value 0.02 ). There was no increase in appearance of string over time.

Table 4: Complications at follow up sessions.

\begin{tabular}{|lllllll|}
\hline Total no. - & \multicolumn{2}{l}{ 6 wks } & \multicolumn{2}{l}{ 6 months } & \multicolumn{2}{l|}{ 1 year } \\
\hline 110 & No & $\%$ & No & $\%$ & No & $\%$ \\
\hline $\begin{array}{l}\text { Menstrual } \\
\text { irregularities }\end{array}$ & 0 & 0 & 14 & 12.7 & 16 & 14.4 \\
\hline Menorrhagia & 0 & 0 & 7 & 6.35 & 5 & 4.3 \\
\hline Fever & 3 & 2.7 & 0 & 0 & 0 & 0 \\
\hline $\begin{array}{l}\text { Vaginal } \\
\text { discharge }\end{array}$ & 1 & 0.9 & 3 & 2.7 & 2 & 1.8 \\
\hline Expulsion & 2 & 1.8 & 0 & 0 & 0 & 0 \\
\hline $\begin{array}{l}\text { Missing } \\
\text { string }\end{array}$ & 40 & 36.3 & 39 & 35.45 & 39 & 35.45 \\
\hline Perforation & 0 & 0 & 0 & 0 & 0 & 0 \\
\hline Failure & 0 & 0 & 0 & 0 & 0 & 0 \\
\hline Removal & 0 & 0 & 0 & 0 & 2 & 1.8 \\
\hline
\end{tabular}

There is no significant association between menstrual complaints and route of insertion. Missing string was significantly higher in the caesarean group ( $\mathrm{P}$ value: 0.02$)$ compared to vaginal insertion.

Majority of the clients were satisfied with PPIUCD insertion $(65.7 \%)$ with only $4.5 \%$ unsatisfied with the procedure. There is no significant association between client satisfaction and route of insertion. 
Table 5: Comparison of menstrual complaints and route of insertion.

\begin{tabular}{|c|c|c|c|c|c|c|c|c|}
\hline \multirow[t]{2}{*}{ Menstrual complaints } & \multicolumn{2}{|c|}{$\begin{array}{l}\text { Vaginal } \\
N-55\end{array}$} & \multicolumn{2}{|c|}{$\begin{array}{l}\text { Cesarean } \\
N-55\end{array}$} & \multicolumn{2}{|c|}{ Total } & \multirow[t]{2}{*}{$\chi^{2}$} & \multirow[t]{2}{*}{ P value } \\
\hline & $\mathbf{N}$ & $\%$ & $\mathbf{N}$ & $\%$ & $\mathbf{N}$ & $\%$ & & \\
\hline 6 weeks & 0 & 0 & 0 & 0 & 0 & 0 & & \\
\hline 6 months & 8 & 14.3 & 6 & 11.1 & 14 & 12.7 & 0.249 & 0.617 \\
\hline 1 year & 9 & 16.4 & 7 & 13 & 16 & 14.7 & 0.252 & 0.616 \\
\hline
\end{tabular}

Table 6: Comparison of fever with route of insertion.

\begin{tabular}{|c|c|c|c|c|c|c|c|c|}
\hline \multirow[t]{2}{*}{ Fever } & \multicolumn{2}{|c|}{$\begin{array}{l}\text { Vaginal } \\
\mathbf{N}-\mathbf{5 5}\end{array}$} & \multicolumn{2}{|c|}{$\begin{array}{l}\text { Caesarean } \\
\mathbf{N}-\mathbf{5 5}\end{array}$} & \multicolumn{2}{|c|}{ Total } & \multirow[t]{2}{*}{$\chi^{2}$} & \multirow[t]{2}{*}{$\begin{array}{l}P \\
\text { value }\end{array}$} \\
\hline & $\mathbf{N}$ & $\%$ & $\mathbf{N}$ & $\%$ & $\mathbf{N}$ & $\%$ & & \\
\hline 6 weeks & 3 & 5.3 & 0 & 0 & 3 & 5.3 & 2.974 & 0.085 \\
\hline 6 months & 0 & 0 & 0 & 0 & 0 & 0 & & \\
\hline 1 year & 0 & 0 & 0 & 0 & 0 & 0 & & \\
\hline
\end{tabular}

Table 7: Comparison of vaginal discharge and route of insertion.

\begin{tabular}{|c|c|c|c|c|c|c|c|c|}
\hline \multirow[t]{2}{*}{ Vaginal discharge } & \multicolumn{2}{|c|}{$\begin{array}{l}\text { Vaginal } \\
\mathrm{N}-55\end{array}$} & \multicolumn{2}{|c|}{$\begin{array}{l}\text { Caesarean } \\
\mathrm{N}=\mathbf{5 5}\end{array}$} & \multicolumn{2}{|c|}{ Total } & \multirow[t]{2}{*}{$\chi^{2}$} & \multirow[t]{2}{*}{$\begin{array}{l}P \\
\text { value }\end{array}$} \\
\hline & $\mathbf{N}$ & $\%$ & $\mathbf{N}$ & $\%$ & $\mathbf{N}$ & $\%$ & & \\
\hline 6 weeks & 1 & 1.8 & 0 & 0 & 1 & 1.8 & 0.974 & 0.324 \\
\hline 6 months & 2 & 3.6 & 1 & 1.9 & 3 & 2.7 & 0.306 & 0.58 \\
\hline 1 year & 1 & 1.8 & 1 & 1.9 & 2 & 1.8 & 0.000 & 0.99 \\
\hline
\end{tabular}

Table 8: Comparison of missing string and route of insertion.

\begin{tabular}{|lllllll|}
\hline \multirow{2}{*}{$\begin{array}{l}\text { Missing } \\
\text { string }\end{array}$} & \multicolumn{2}{l}{ Vaginal } & \multicolumn{2}{l}{ Caesarean } & \multicolumn{2}{l}{ Total } \\
\hline Yes & $\mathbf{N}$ & $\mathbf{\%}$ & $\mathbf{N}$ & $\mathbf{\%}$ & $\mathbf{N}$ & $\mathbf{\%}$ \\
\hline No & 14 & 25 & 26 & 48.15 & 40 & 36.36 \\
\hline Total & 42 & 75 & 28 & 51.85 & 70 & 63.63 \\
\hline$\chi^{2}=5.404 ;$ & df $=1 ; \mathrm{P}=0.020$ & 100.0 & 54 & 100.0 & 110 & 100 \\
\hline
\end{tabular}

Overall evaluation of the study shows that PPIUCD is demonstrably safe and effective long term contraception. There is no significant difference in safety and efficacy depending on the route of insertion. In fact, ease of insertion at caesarean and lower risk of expulsion makes it a very attractive option for those undergoing caesarean section.

\section{DISCUSSION}

Helping couples understand their risk of unplanned pregnancy and ensuring that high quality postpartum family planning services are available to them is the objective of an ideal contraceptive counseling. Linking maternal child health and family planning services is critical to achieve healthy spacing of pregnancy (HSP). This led to the revival of post-partum IUCD in 2010. As part of the national training programme, we at SAT hospital, Government Medical College, Kerala conducted the study on the clinical and sociodemographic profile of acceptors and the efficacy and safety of PPIUCD inserted by vaginal and caesarean routes.

Table 9: Client satisfaction and type of insertion.

\begin{tabular}{|c|c|c|c|c|c|c|}
\hline $\begin{array}{l}\text { Satisfaction } \\
\text { score }\end{array}$ & \multicolumn{2}{|c|}{$\begin{array}{l}\text { Vaginal } \\
\mathbf{N}-\mathbf{5 5}\end{array}$} & \multicolumn{2}{|c|}{$\begin{array}{l}\text { Caesarean } \\
\mathbf{N}-55\end{array}$} & \multicolumn{2}{|c|}{ Total } \\
\hline & $\mathbf{N}$ & $\%$ & $\mathbf{N}$ & $\%$ & $\mathbf{N}$ & $\%$ \\
\hline Not satisfied & 2 & 3.63 & 3 & 5.45 & 5 & 4.5 \\
\hline Un sure & 15 & 26.8 & 16 & 29.1 & 31 & 27.9 \\
\hline Satisfied & 34 & 16.7 & 31 & 56.4 & 65 & 58.6 \\
\hline Very satisfied & 4 & 7.1 & 4 & 7.1 & 8 & 7.1 \\
\hline
\end{tabular}

$\chi^{2}=2.362 ; \mathrm{df}=3 ; \mathrm{p}$ value: 0.670

The study showed that maternal age is an important factor in contraceptive acceptance. A study by Usha Ram et al have shown that the unmet need for family planning is alarmingly high among those aged $20-24$ years (15\%) for spacing and over $6 \%$ for limiting method. ${ }^{3}$ Our study showed that $50 \%$ of the acceptors belonged to $20-25$ years of age showing the need to catch them young for proper spacing and limiting of births. .In a study published by a teaching institution in Nigeria showed the model age group of clients was 25-29 years $(32.5 \%)$ among 852 IUCD acceptors. ${ }^{4}$ 
In the present study, acceptance of PPIUCD was more common among multiparas $(73.3 \%)$ compared to primis (26.7\%). According to Rivero-Fuentes et al women's' preference of beginning contraception is influenced by their knowledge about post-delivery return of fertility, limitations of LAM and resumption of sexual activity (40\% in $<3$ months and $90 \%$ by one year) hence focus should be on young primiparas who are reluctant to return for interval contraception. ${ }^{5}$

Majority of participants accepted the method when they were given information during early labour (65\%) compared to antenatal counseling (44\%). Those patients who were willing to accept during the antenatal period become reluctant later as they are more exposed to rumors and myths regarding copper T. Many studies have shown that when the husband is involved in counseling and decision making the acceptance and continuation rates were higher. A randomized prospective study conducted by Smith et al in antenatal clinics in China, Scotland and South Africa in which some women received information on contraception in antenatal care and some did not, found no difference in subsequent contraceptive use. ${ }^{6}$ Another study by Mohammed. SA et al to evaluate factors affecting acceptance found the same rate during antenatal and post-partum counseling. ${ }^{7}$ However; providing key essential messages at all contact points during the maternity cycle will increase the proportion of women who received the information and are able to make an informed decision.

Copper IUDS are often associated with an increased amount of menstrual bleeding. Pareek and Gandhi reported an excessive bleeding rate of $6.6 \%$ with cesarean insertions. ${ }^{8}$ Shukla et al indicated a higher incidence of menorrhagia (27.2\%) with use of Copper T 200 as interval insertion. ${ }^{9}$ While Gupta et al observed bleeding in only $4.3 \%$ PPIUCD cases using Copper T 380A. ${ }^{10}$ Difference in types of IUCD could possibly explain the different rates of bleeding problems. The present study showed no significant association of menstrual complaints with the route of insertion and significant menorrhagia at the end of one year was only $4.3 \%$.

Women with IUCDs are more apprehensive regarding the symptom of vaginal discharge. In women reporting with symptoms of unusual discharge actual infection was extremely low on clinical evaluation. A multicentric study from India reported an overall infection rate of $4.5 \%$ with PPIUCD. ${ }^{11}$ Welkovic et al compared the infection rate among IUCD users and non-users and found no difference. ${ }^{12}$ Present study showed only $1.8 \%$ vaginal discharge and there was no significant association between vaginal discharge and route of insertion.

Expulsion rates of immediate PPIUCD showed controversial results. There is debate whether difference in expulsion rates are related to the time of insertion, type of IUCD, technique of insertion and skill and expertise of service provider. Expulsion of PPIUCD usually occurs in the first few months after insertion. A study by Eroglu K et al expulsion rates are higher with postpartum insertion (within 48 hrs of delivery) than immediate post placental insertion (within 10 minutes of placental delivery). ${ }^{1,3} \mathrm{UN}$ POPIN report stated 6 month cumulative expulsion rate of $9 \%$ for post placental compared with $37 \%$ for postpartum insertions. ${ }^{14}$

Gupta et al reported lower expulsions after cesarean insertions than vaginal delivery. In the present study we had no expulsion in the cesarean group while 2 cases of expulsion occurred in the vaginal delivery group. ${ }^{10}$ Still we have a commendable IUCD continuation rate of $98 \%$. This has emphasis on the correct fundal placement of the device and avoiding downward displacement both during vaginal and cesarean insertions.

In the present study, there was no case of perforation or failed IUCD as the uterine wall is thick after delivery and uterine perforation is unlikely to occur during postpartum period.

One of the main observations at follow up was the missing strings. Turan et al reported missing string rate in interval IUCD insertion to be $15.6 \% .{ }^{16}$ But there was limited literature regarding missing strings in PPIUCD insertion. Present study showed the significantly high occurrence of missing strings with postpartum IUCD $(34.5 \%)$. This was significantly higher with cesarean placements than with vaginal insertions (48.5\% versus $25 \%$ ). However ultrasound done showed PPIUCD insitu and counseling and reassurance encouraged them to continue with the device.

\section{CONCLUSION}

IPPIUCD is an effective safe and convenient method of contraception which can be integrated with maternal child health services ensuring an appropriate long term reversible family planning method before returning home. It is an effective intervention in both cesarean and vaginal deliveries with no significant difference in safety and efficacy depending on the route of insertion. A relatively higher incidence of expulsion after vaginal insertion can be taken care of by trained personals with emphasis on the immediate post placental timing of insertion and principles of fundal placement using long placental forceps.

Misconceptions and negative attitudes related to IUCD should be addressed through community based activities and government strategies to increase public awareness through different media sources. It is important to arrange training programmes for health providers to increase knowledge and skills on IUCD insertion. This will further promote PPIUCD use and aid in reduction of expulsion rates. Sharing positive experiences from satisfied PPIUCD users is another way of promoting the programme. Obstetricians rather than family planning medical officers have a crucial role to play in 
implementing the programme as counselling is exclusively done in the antenatal and early intrapartum period. PPIUCD is therefore a strong weapon in the family planning armamentarium and should be encouraged in both vaginal and caesarean deliveries.

\section{ACKNOWLEDGEMENTS}

Authors would like to thank Dr. Aswathy S and deep regards to Dr. Sujamol Jacob, Addl. Professor, Department of Obstetrics and Gynecology, Government Medical College, Trivandrum for her exemplary guidance, monitoring and constant encouragement throughout the course of the study. Authors would also like to express their deep sense of gratitude to Dr. Nirmala C, Professor and Head of Department of Obstetrics and Gynecology for her support and guidance. Authors also wish to express his gratitude to Dr. P. K. Babu, Asst. Professor, statistics and Demography for helping me with the analysis. Authors also thank Ms. Devi. V, Computer Assistant and other staff members of the department who rented the help in his study.

\section{Funding: No funding sources}

Conflict of interest: None declared

Ethical approval: The study was approved by the Institutional Ethics Committee

\section{REFERENCES}

1. Family Planning Needs during Extended PostPartum Period in Asia: USAID/ACCESS 2009.

2. Postpartum IUCD reference manual, Family Planning Division. Ministry of Health and Family Welfare, Government of India, New Delhi, India, 2010.

3. Usha Ram, Ph.D. Associate Professor, Dept. of Public health and Mortality Studies, International Institute for Population Sciences, MUMBAI- paper presentation in the International Conference on Family Planning, November 15-18, 2009 at Munyonyo, Uganda.

4. Barbara Deller for Elaine Charurat, Postpartum IUCD (PPIUCD): opportunities for a languishing innovation. 2007.
5. Rivero-Fuentes, Estela. 2008: Original data analysis of data sets from the Dominican Republic, Haiti and Nicaragua used in Quuiteroetal. 2007.

6. Smith KB. Is postpartum contraceptive advice given antenatal of value? Contraception. 2002;65(3):23743.

7. Mohamed SA, kamel MA, Shaaban OM, Salem HT. Acceptability for the use of postpartum intrauterine contraceptive devices. Med Princ Pract. 2003;12(3):170-5.

8. Parikh V, Gandhi AS. Safety of Copper $\mathrm{T}$ as contraceptive After Cesarean Section. J Indian Med Assoc. 1989-87:113-5.

9. Shukla M, Qureshi S. Post-placental intrauterine device insertion - a five year experience at a tertiary care center in North India. Indian Journal of Medical Research. 2012;136(3):432-5.

10. Gupta A, Verma A, Chauhan J. Evaluation of PPIUCD versus interval IUCD 380 A insertion in a teaching hospital of Western UP. International Journal of Reproduction, Contraception, Obstetrics and Gynecology. 2013;2:204-8.

11. Sood B, Asif R. Revitalization of postpartum IUCD (PPIUCD) services: experience from India. Contraception. 2012;86(2):184-5.

12. Welkovic S, Costa L. Post-partum bleeding and infection after post-placental IUD insertion: Contraception. 2001;63(3):155-8.

13. Eroglua K, Akkuzu G. Comparison of efficacy and complication of IUD insertion in immediate post placental and early postpartum period with 1 year follow up. Contraception. 2006;74:376-81.

14. United Nations population Information Network (POPIN). UN population division. Department of Economic and Social Affairs with Support from UN Population Fund. Network Intrauterine devices. Family Health International. 1996;16(2).

Cite this article as: Aswathy S, Jacob S, Nirmala C. Outcome of immediate postpartum intrauterine contraceptive device in caesarean versus vaginal insertion: a comparative study. Int J Reprod Contracept Obstet Gynecol 2017;6:694-9. 